\title{
GLOBAL MESOSPHERIC TIDAL WINDS OBSERVED BY THE HIGH RESOLUTION DOPPLER MMAGER ON BOARD THE UPPER ATMOSPHERE RESEARCH SATELLTTE
}

\author{
Y. T. Morton, R. S. Lieberman, P. B. Hays, D. A. Ortland, A. R. Marshall, \\ D. Wu, W. R. Skinner, M. D. Burrage, D. A. Gell and J.-H. Yee*
}

\section{Space Physics Research Laboratory, University of Michigan}

\begin{abstract}
This paper presents preliminary results of a study of mesospheric and lower thermospheric diumal tidal winds obtained with the High Resolution Doppler Imager (HRDI) on the Upper Atmosphere Research Satellite (UARS). Zonal averages of the meridional and zonal wind fields are performed at fixed local times. These analyses reveal tidal structures in the mean meridional wind field during the months of February and March 1992. Results are presented for a typical day in February 1992. The observed maximum amplitude of meridional wind is approximately $75 \mathrm{~m} \mathrm{~s}^{-1}$. The observed vertical wavelength is about $20 \mathrm{~km}$, with amplitudes increasing linearly with height. In addition to the tides, the zonal wind field reveals many features of the mesospheric climatological mean zonal wind.
\end{abstract}

\section{Introduction}

In the past decade there has been considerable progress in both theoretical and observational studies of middle atmospheric tides. Vial and Forbes [1989] and Vial [1989] have presented comprehensive reviews of recent advances in tidal modeling. The classical tidal theory of Chapman and Lindzen [1970], which is valid for inviscid perturbations to a resting basic state, does not provide an adequate theoretical framework for mesospheric and thermospheric tides. Forbes [1982] has developed a global model which incorporates ion drag, eddy diffusion, mean winds, background temperature structure and hydromagnetic coupling. The calculation of the main propagating diurnal tide, however, is carried out with an equivalent gravity wave approximation, which neglects the effects of mean winds and meridional temperature gradients [Lindzen, 1970; Forbes and Hagan, 1979]. This approximation was subsequently dropped in the work of Vial [1986] and in later studies by Forbes and Hagan [1988] and Forbes and Vincent [1989]. These improved models yield results which differ significantly from Forbes' earlier predictions; however, due to the extensive documentation and tabulation of the 1982 model by Forbes and Gillette [1982], we retain their calculations for comparison with observed winds.

Observational studies of middle atmosphere tides have relied heavily on ground based radio wave techniques such as incoherent scatter (VHF) and MF radars [Manson et al., 1985; Salah et al., 1991; Vincent et al., 1988]. These data, however, are limited to a few geographic locations.

*J.-H. Yee now at Applied Physics Laboratory, Johns Hopkins University, Laurel, MD 20723-6099

\section{Copyright 1993 by the American Geophysical Union.}

Paper number 93GL00826

0094-8534/93/93GL-00826\$03.00
Simultaneous observations of the diurnal tides at different radar sites often reveal inconsistencies that are generally attributed to local influences, which cannot be separated from the global structure of the tides.

Polar and circular-orbiting satellites provide long-term, continuous global coverage of the middle atmosphere. The High Resolution Doppler Imager (HRDI) on board the Upper Atmosphere Research Satellite (UARS) has been observing winds in the stratosphere, mesosphere, and lower thermosphere since November, 1991. Previous studies have successfully demonstrated the feasiblilty and methodology of obtaining global tidal analyses from sun-synchronous satellite measurements [Brownscombe et al., 1985; Hitchman and Leovy, 1985; Lieberman, 1991]. This study employs similar techniques to infer the structure of mesospheric and lower thermospheric diurnal tides from HRDI observations.

\section{Measurements and Analysis Procedures}

HRDI is a triple-etalon Fabry-Perot interferometer/photometer which measures the Doppler shift of the $\mathrm{O}_{2}$ atmospheric band $\left(b^{1} \Sigma_{g}^{+}-X^{3} \Sigma_{g}^{-}\right)$absorption and emission features. The study presented here is restricted to the 60-100 km range. Over most of this region, HRDI measurements are possible only during daylight hours, with the exception of the $95 \mathrm{~km}$ level where both daytime and nighttime emissions are observed. Line of sight wind velocities are measured from two nearly orthogonal directions to yield horizontal vector winds. The vertical resolution of the wind profiles is about $2.5 \mathrm{~km}$. Further discussions of the instrument and the determination of the wind profiles are found in Hays et al. [1993] and Abreu et al. [1989].

UARS is stabilized in a circular orbit $585 \mathrm{~km}$ above the Earth's surface, with an inclination of $57^{\circ}$. This allows HRDI measurements to extend as far poleward as $74^{\circ}$. The resolution along the orbit track is about $500 \mathrm{~km}$. The satellite completes about 15 orbits per day, while the the Earth rotates beneath it. From the standpoint of an earthbound observer, the observing points drift westward along a latitude circle at the rate of about $365^{\circ}$ of longitude per day. This corresponds to a 20-minute change in the local time of a subsequent days' measurement. About 72 days are thus required for all local solar times to be sampled by the satellite on a single node.

This paper focuses on the wind observations for February 12,1992 , which represents a typical day for the FebruaryMarch 1992 observing period. Figure 1 shows the latitudelongitude mapping of the $90 \mathrm{~km}$ wind vectors for this day. The corresponding local solar time and latitude coverage are plotted in Figure 2. If only the migrating tides were present, there would be virtually no longitudinal variation in the pattern observed in Figure 1. The contribution of the migrating tidal component at a fixed local time is isolated by daily averaging of the winds at each latitude circle over all longitudes 


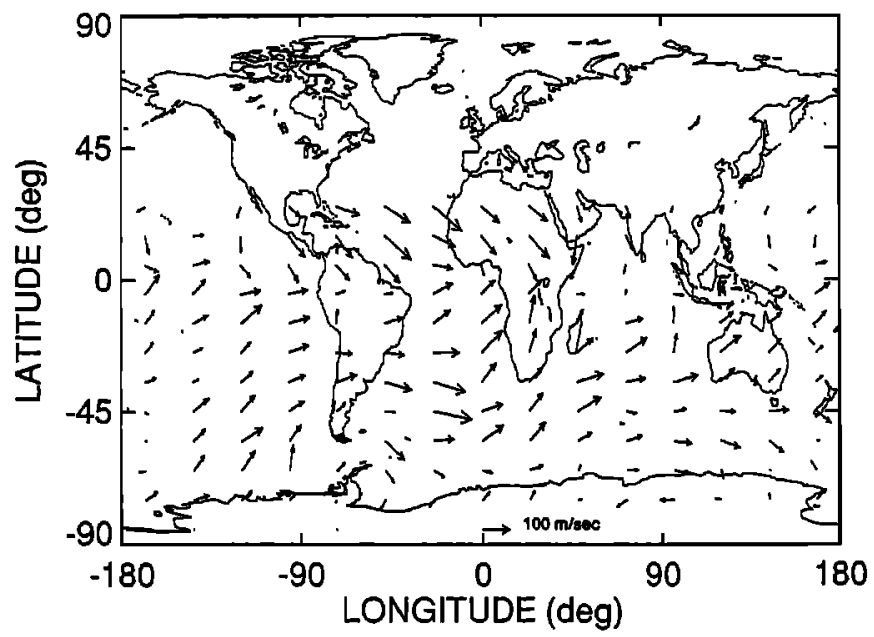

Fig. 1. HRDI horizontal winds at $90 \mathrm{~km}$ for Feb. 12, 1992.

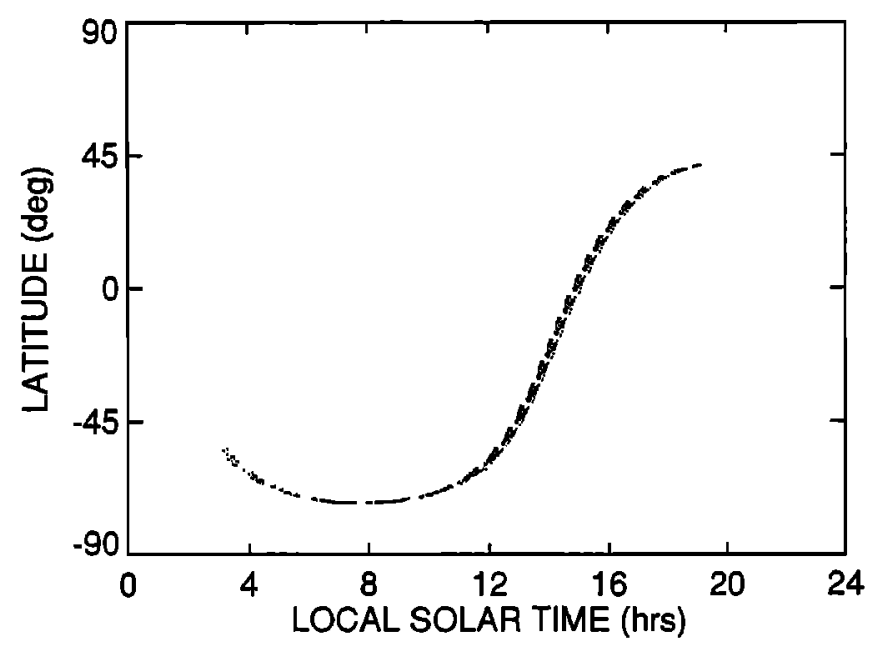

Fig. 2. Local time vs. latitude coverage for Feb. 12, 1992.

[Hitchman and Leovy, 1985; Brownscombe et al., 1985; Hays et al., 1992]. The remaining discussions will focus on the latitude-height distributions of these zonally-averaged fields. It is important to note that, along with the migrating tides, the longitudinal averaging process also enhances the stationary component of the zonal mean fields [Salby, 1982]. This point is further discussed in the section on HRDI zonal winds.

\section{Meridional Wind}

Figure 3a shows the latitude-height distribution of the zonally-averaged meridional wind. Solid contours indicate northward winds while the dotted contours represent southward winds. The northern hemisphere is characterized at low latitudes by a southward wind field at $70 \mathrm{~km}$ and a northward wind cell centered at $83 \mathrm{~km}$. The wind fields continue to alternate direction every $10 \mathrm{~km}$ or so in altitude. The magnitudes of the winds increase with height, from $10 \mathrm{~m}$ $\mathrm{s}^{-1}$ at $70 \mathrm{~km}$ to about $70 \mathrm{~m} \mathrm{~s}^{-1}$ at $100 \mathrm{~km}$. In the southern hemisphere a similar but reversed pattern is observed.

The observed meridional wind field is very suggestive of the migrating diurnal tide. To verify this point we compare it with the values reported by Forbes and Gillette [1982] for the diumal meridional winds at winter solstice. The model results are shown in Figure 3b, from which the similarities with HRDI data can be clearly seen. Both fields show the dominant lobes centered on the $25^{\circ}-30^{\circ}$ latitude region in each hemisphere. The patterns are antisymmetric about the equator, and decrease gradually in intensity poleward of $30^{\circ}$. At low latitudes, the observed wind exhibits oscillatory vertical structure, with a wavelength of about $20 \mathrm{~km}$. From Figure $3 \mathrm{~b}$, the model vertical wavelength is roughly $25 \mathrm{~km}$. The discrepancy in wavelength is probably due to the effects of the background temperature and mean wind, which were neglected in the model calculation. Both the calculated and the observed amplitudes increase with height in a quasi-linear fashion.

The semidiumal tidal wind field has also been calculated from the model of Forbes [1982]. The addition of the semidiumal to that of the model diurnal tide did not improve the comparison with the measurement. Most of the modification introduced by the semidiumal tide occurs at above $95 \mathrm{~km}$ altitude and in mid- to high-latitude regions. We conclude that the diurnal tide is the dominant feature of the HRDI daily mean meridional wind.

\section{Zonal Wind}

Figure 4a shows the latitude-height distribution of the zonally-averaged zonal wind for February 12, 1992. Solid lines indicate westerly winds and dotted lines represent easterly winds. The zonal wind component of the Forbes model diurnal tide is shown in Figure $4 \mathrm{~b}$. A comparison between these two figures suggests that while there is some indication of the diumal tide embedded in the HRDI wind structure, the two patterns are quite dissimilar. In order to interpret the observations, the Forbes and Gillette diurnal zonal winds are subtracted from the HRDI zonal wind field. To obtain better global coverage, four days of measurements (February 12, 13,15 , and 16, 1992) are used in this calculation. The result is plotted in Figure 5a.

At middle and high latitudes, the HRDI zonal mean wind field exhibits the salient features of the climatological zonal mean wind. In Figure 5b, we have plotted the COSPAR International Reference Atmosphere (CIRA) mean zonal wind for the month of February. Below $85 \mathrm{~km}$, the HRDI wind field is characterized by mesospheric westerlies in the northern hemisphere, and easterly flow in the southern hemisphere. Above $85 \mathrm{~km}$, the winds become westerly throughout the southern hemisphere. In the northern hemisphere, HRDI delineates a region of transition to easterly flow above $85 \mathrm{~km}$ poleward of $50^{\circ}$. The magnitudes of the HRDI winds show good general agreement with the CIRA values.

At low latitudes the HRDI wind field contains features which are not observed in the CIRA dataset. These include a westward jet centered at $80 \mathrm{~km}$ above $10^{\circ} \mathrm{S}$. A weaker westward jet positioned at $100 \mathrm{~km}$ above the equator is flanked on the northward side by an eastward jet centered on $30^{\circ} \mathrm{N}$. It is interesting to note that except for these localized wind maxima, the pattern of equatorial zonal mean winds resembles the CIRA climatology. The jet at $85 \mathrm{~km}$ may be related to the easterly phase of the mesospheric semiannual oscillation (SAO) in the zonal mean wind. Hirota [1978], Hamilton [1982] and Palo and Avery [1992] have reported a 

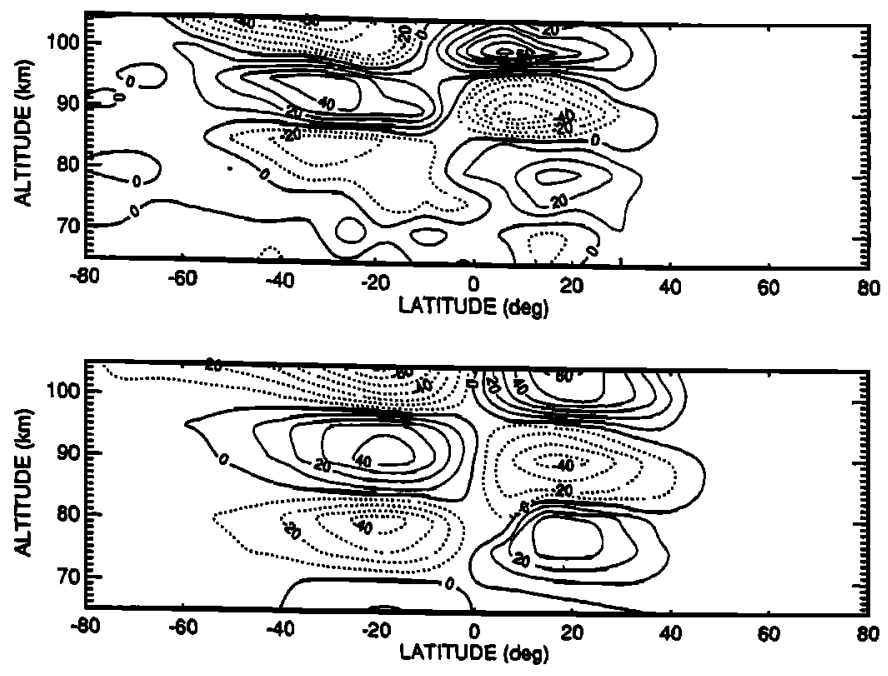

Fig. 3. (a) HRDI zonal averaged meridional wind for Feb. 12, 1992. (b) Diurnal meridional winds at winter solstice (from Forbes and Gillette, 1982).
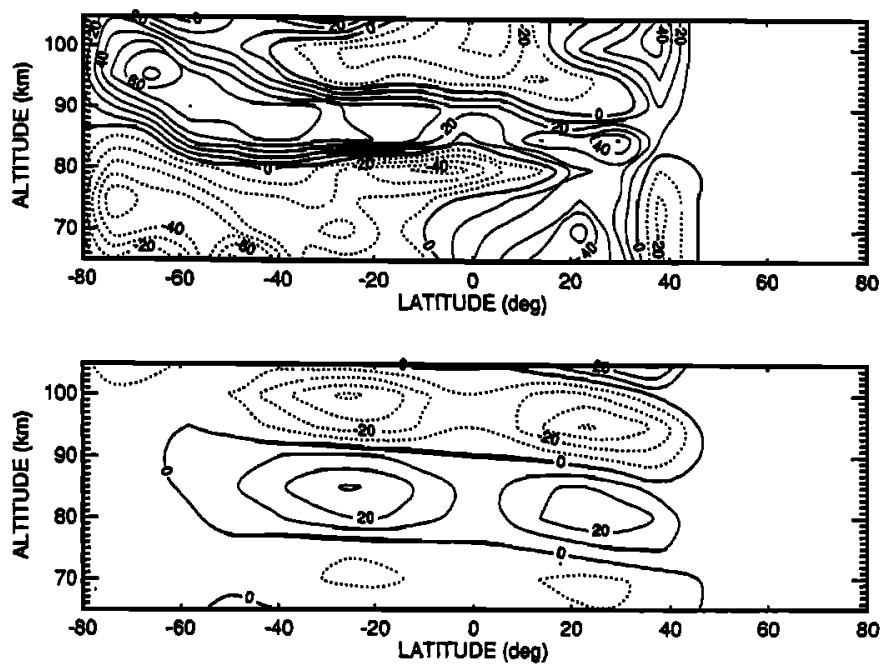

Fig. 4. As in Figure 3, for the zonal wind component.
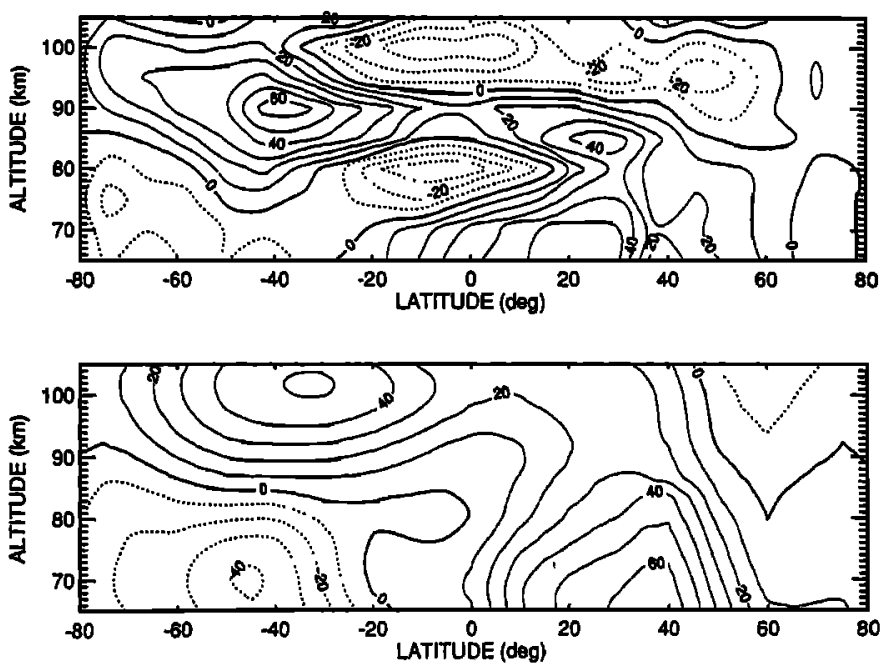

Fig. 5 (a) Background zonal wind inferred from HRDI measurements. (b) CIRA February zonal mean winds. 
maximum in the SAO near $80 \mathrm{~km}$ at equatorial latitudes. Forbes et al. (Acceleration, heating and compositional mixing of the thermosphere due to upward-propagating tides, submitted to J. Geophys. Res., 1992) have examined the response of the zonal mean wind to tidal accelerations in the NCAR Thermospheric-Ionospheric General Circulation Model. They report the formation of equatorial lower thermospheric jets which qualitatively resemble the equatorial wind structures described in the HRDI observations at 100 $\mathrm{km}$. Further observations of the equatorial zonal mean winds are required in order to interpret the patterns inferred from HRDI zonal wind averages.

\section{Summary and Conclusions}

We have presented our preliminary results based on an examination of HRDI mesospheric winds on February 12-16, 1992. The solar diumal tide is the dominant feature in the meridional wind field. The observed vertical wavelength is about $20 \mathrm{~km}$, and the amplitudes increase linearly with height by $2 \mathrm{~m} \mathrm{~s}^{-1}$ per $\mathrm{km}$. These observation are generally consistent with the predictions of Forbes and Gillette [1982]. We emphasize that the tidal results presented in this paper pertain to one local solar time. Future studies will address the local time dependence of the tides observed by HRDI

The agreement between HRDI mean meridional winds and theoretical diumal wind predictions implies that the stationary component of the mean meridional wind field is of small magnitude. However, comparisons of HRDI zonal mean winds with CIRA climatology and with the Forbes and Gillette [1982] model indicate that the background wind, rather that the migrating tide, dominates the HRDI zonal mean winds. At extratropical latitudes, HRDI measurements compare favorably with the CIRA zonal mean winds. At low latitudes, the HRDI measurements reveal features which do not appear in the CIRA data. Possibly these patterns are related to the SAO and tide-mean flow interactions. The evolution of the HRDI zonal mean wind field is currently being examined in greater detail.

\section{References}

Abreu, V. J., A. Bucholtz, P.B. Hays, D.A. Ortland, W.R. Skinner, and J.-H. Yee, Absorption and emission line shapes in the $\mathrm{O}_{2}$ atmospheric bands: Theoretical model and limb viewing simulations, Applied Optics, 28, 21282137, 1989.

Brownscombe, J. L., J. Nash, G. Vaughan and C. F. Rodgers, Solar tides in the middle atmosphere. I: Description of satellite observations and comparison with theoretical calculations at equinox, Quart. J. R. Met. Soc., $111,677-689,1985$.

Chapman, S., and R. S. Lindzen, Atmospheric Tides, Gordon and Breach, 1970.

Forbes, J. M., Atmospheric tides I. Model description and results from the solar diurnal component, $J$. Geophys. Res., 87, 5222-5240, 1982.

Forbes, J. M. and D. F. Gillette, A compendium of theoretical atmospheric tidal structures, Rep. AFGL TR 82-0173, 1982.

Forbes, J. M., and M. E. Hagan, Tides in the joint presence of friction and rotation: An f-plane approximation, $J$. Geophys. Res., 84, 803-810, 1979.

Forbes, J. M., and M. E. Hagan, Diurnal propagating tide in the presence of mean winds and dissipation: a numerical investigation, Planet. Space Sci., 37, 579-590, 1988.

Forbes, J. M., and R. A. Vincent, Effects of mean winds and dissipation on the diumal propagating tide: An analytic approach,Planet Space Sci., 37, 197-209, 1989.

Hamilton, K., Rocketsonde observations of the mesospheric semiannual oscillation at Kwajalein, Atmos.-Ocean, 20, 281-286, 1982.

Hays, P. B., V. J. Abreu, M. E. Dobbs, D. A. Gell, H. J. Grassl, and W.R. Skinner, The High Resolution Doppler Imager on the Upper Atmosphere Research Satellite, J. Geophys. Res., in press, 1993.

Hirota, I., Equatorial waves in the upper stratosphere and mesosphere in relation to the semiannual oscillation of the zonal wind, J. Atmos. Sci., 35, 714-722, 1978.

Hitchman, M. H. and C. B. Leovy, Diurnal tide in the equatorial middle atmosphere as seen in LIMS temperatures, J. Atmos. Sci., 42, 557-561, 1985.

Lieberman, Ruth S., Nonmigrating diumal tides in the equatorial middle atmosphere, $J$. Atmos. Sci., 48, 1112 $1123,1991$.

Lindzen, R. S., Internal gravity waves in atmosphere with realistic dissipation and temperature. Part I: Mathematical development and propagation of waves into thermosphere, Geophys. Fluid Dyn., I, 303-355, 1970.

Manson, A. H., C. E. Meek, M. J. Smith, and G. J. Fraser, Direct comparison of prevailing winds and tidal wind fields (24-, 12-h) in the upper middle atmosphere (60-105 $\mathrm{km})$ during 1978-1980 at Saskatoon $\left(52^{\circ} \mathrm{N}, 107^{\circ} \mathrm{W}\right)$ and Christchurch ( $\left.44^{\circ} \mathrm{S}, 173^{\circ} \mathrm{E}\right), \mathrm{J}$. Atmos. Terr. Phys., 47 , 463-476, 1985.

Palo, S. E. and S. K. Avery, Mean winds and the semiannual oscillation in the mesosphere and lower thermosphere at Christmas Island, Chapman Conf. on the Upper Mesosphere and Lower Thermosphere, Nov. 16-20, 1992.

Salah, J. E., R. M. Johnson, and C. A. Tepley, Coordinated incoherent scatter radar observations of the semidiurnal tide in the lower thermosphere, J. Geophy. Res., 96, 1071-1080, 1991.

Salby, Murry L., Sampling theory for asynoptic satellite observations. Part I: Space-time spectra, resolution, and aliasing, J. Atmos. Sci., 39, 2577-2600, 1982.

Vial, F., Numerical simulations of atmospheric tides for solstice conditions, J. Geophys. Res., 91, 8955-8969, 1986.

Vial, F., Tides in the middle atmosphere, J. Atmos. Terr. Phys., 51, 3-17, 1989.

Vial, F., and J. M. Forbes, Recent progress in tidal modeling, J. Atmos. Terr. Phys., 51, 663-671, 1989.

Vincent, R. A., T. Tsuda, and S. Kato, A comparative study of mesospheric solar tides observed at Adelaide and Kyoto, J. Geophy. Res., 93, 699-708, 1988.

M.D. Burrage, D. A. Gell, P. B. Hays, R. S.

Lieberman, A. R. Marshall, Y. T. Morton, D. A. Ortland, W. R. Skinner, and D. Wu, Space Physics Research Laboratory, University of Michigan, Ann Arbor, MI 48109-2143

(Received February 1, 1993; accepted March 5, 1993.) 